\title{
Research on English Learning Model of Higher Vocational College Based on Superstar Platform Learning System
}

\author{
-Taking Superstar APP as an Example
}

\author{
Baomei Huang* \\ Dept. of Ideological and Political Teaching \& Research \\ Guangxi Vocational \& Technical College \\ Nanning, China
}

\author{
Chunzhong $\mathrm{Yu}$ \\ Audit Office \\ Guangxi Vocational \& Technical College \\ Nanning, China
}

\begin{abstract}
To investigate the influence of hybrid teaching mode on multiliteracies ability of higher vocational students', the paper makes the empirical study of English design learning model using Superstar Platform Learning System. It is integrated into design learning concept, which includes three-stage of "before-class preparation" "in-class online and offline hybrid intelligent learning" and "after-class review" according to English design learning model of higher vocational college. Meanwhile, this paper analyzes the influence of this model on students' reading and writing ability and students' attitude towards this model through a questionnaire survey, random interview and empirical experiment. The result shows that the model was very popular among students and effectively strengthened students' multiliteracies. Superstar Platform Learning System can automatically collect all learning quantify students' learning effect in real-time, and promote the transformation of teaching from experience-driven to datadriven. It's really helpful to accurate diagnosis and improvement of teaching quality. The results of the paper also provide a useful reference for the cultivation of higher vocational college students, the application and promotion of English learning and modern teaching technology in English learning.
\end{abstract}

Keywords-Superstar Platform Learning System (SPLS); design learning; multiliteracies; higher vocational English course; Superstar APP

\section{INTRODUCTION}

In recent years, mobile Internet users sustain high growth. China Internet information center (CNNIC) resealed the $42^{\text {nd }}$ statistical report on internet development in China on August 20, 2018, in Beijing. As of June 2018, China had 788 million mobile Internet users, with $98.3 \%$ of them accessing the Internet via mobiles phones, according to the report[1]. With such background, the teaching platform of various mobile terminal comes into being, especially "Superstar Platform Learning System”, "Blue Ink Cloud Class”, "Rain Classroom”. These excellent mobile teaching platforms have become effective tools and powerful assistants for college classrooms

1. Research on the influencing factors of higher vocational college students' independent English Learning Based on online and offline blended teaching (Guangxi Vocational \& Technical College).

2. Research on the professional development of higher vocational English teachers in Guangxi in the new era. (Guangxi Vocational \& Technical College to innovate teaching methods and means and improve teaching quality.

\section{BASIC CONCEPTS}

\section{A. The concept of Superstar Platform Learning System (SPLS)}

Superstar Platform Learning System (SPLS) is a course learning, knowledge dissemination and management sharing platform launched by superstar based on microservice architecture. APP of SPLS has functions of cloud disk sharing, multi-terminal data transfer, classroom exercise answering system, bullet screen classroom discussion, notes, instant recording and live broadcast of topics, data collection and analysis, etc. After class, students can use the fragmented time to carry out mobile independent learning on SPLS, including multi-mode PPT with voice explanation, submitting text, picture voice and other forms of submitting text, pictures, voice and other forms of homework. In class, SPLS combines traditional learning activities with mobile phones terminal learning, endowing conventional learning with new manifestation. In particular, timed answers, bullet screens and random roll call can enhance students' learning experience. SPLS can automatically collect all learning quantify students' learning effect in real-time, and promote the transformation of teaching from experience-driven to data-driven. It's really helpful to accurate diagnosis and improvement of teaching quality.

Starting from the spring semester of 2017, Guangxi Vocational \& Technical College began to fully implement online course using SPLS. Relevant research findings show that the intervention of Superstar learning platform technology plays a positive incentive role in the learning process[2]. It shows with a positive impact on teaching design, learning behavior and teaching decision-making. It is not only conducive to improving students' participation in learning, improving students' learning efficiency and strengthening, learning efficiency and interaction between teachers and students, but also conducive to teachers' in-depth understanding of students' learning behavior characteristics to improve teaching quality. 


\section{B. Multiliteracies}

The New London Group came up with the concept of Multiliteracies [3]. It is believed that traditional reading-writing and read-reading abilities cannot meet the requirements of learners, and it is necessary to cultivate learners' creative use of information and communication technologies to critically read and understand the information provided by multi-media through language, vision, hearing and other multi-form. Zhang Delu believes that Multiliteracies include language literacy, social communication competence and technical literacy [4]. Among them, language literacy refers to listening, speaking, reading, writing and translating abilities. Social communication skills contain cultural literacy, critical literacy and other abilities. Students are required to have a profound cultural background and critical ability of target language, as well as the ability to understand and adapt to diverse cultures. Technical literacy requires students to have the knowledge and ability of modern media technology, such as, to grasp not only the affordance and meaning potential of technology modality but also the affordance and meaning potential of the technology

\section{Design learning}

The main theoretical basis for the development of multiple literacies is the new London group's “design learning”[5]. The theory maintains that learning needs to be actively designed, teachers only provide learning conditions and requirements, and students need to choose appropriate modes or modal combinations to achieve meaning and become positive meaning creators.

\section{CONSTRUCTION OF ENGLish Design LEARNING Model IN Higher Vocational COLLEGE BASED ON SPLS}

The English design learning model based on SPLS should be aimed at cultivating students' multiple reading and writing ability. From a design learning perspective, some problems students encounter in learning English coursed in vocational colleges, such as the personal experience of new knowledge, conceptual and theoretical study, functional analysis and appropriate application of efficiency is not efficient [6]. Too little time for the first-hand experience with existing knowledge, critical analysis, and creative application leads to poor multiliteracy. In order to cultivate students' multi-literacy ability and improve the effect of higher vocational English learning, this study constructs a learning model of English design based in SPLS. Driven by the task of completing each project, it adopts online and offline mixed teaching mode, using mobile learning and big data analysis to give students timely and resultful teaching feedback. It consists of three stages of "before-class preparation", "in-class online and offline hybrid intelligent learning" and "after- class review".

The following explains the detailed operation of design learning mode. The textbook is Career Express English Students' Book I, which is published by Higher Educational Press in 2017[7]. The author chooses Unit 4 -SPORTS, Text A, Chinese Kung-fu as an example.

\section{A. Before class-preparation}

In the pre-class previews stage, students mainly experience new background knowledge and learn theoretical through video, micro-class and PPT on SPLS. On the one hand, students learn multimodal preview PPT by themselves to experience new background knowledge. The Multi-modal of theme introduction and background knowledge is designed by teachers in combination with cultural and situation context factors related to the unit theme Sports, which is in accordance with the principle of multi-modal selection of foreign language teaching. Students are in a highly simulated context constructed from symbolic resources, for instance, text, pictures, audio and video. Students can experience Chinese Kung-fu, Shaolin Temple, Drunken Boxing, Tai Chi Boxing and other closely related to the topical subject of cultural knowledge, and information about the author and other cultural information with the infiltrating type. Students do some exercises online, e.g. vocabulary quizzes, match the proper words with the picture and think about the question "What sports do you usually do when you have PE classed?”. On the other hand, students need to preliminarily learn the theoretical concept of autonomous learning. That is reading the text quickly and browsing the key words and phrases highlighted with red color in the PPT of language points of the text, as well as key sentences patterns highlighted with underline or italics.

\section{B. In class-SPLS online and offline hybrid learning}

Classroom learning is conducted in the form of face-to-face teaching and SPLS. The specific process is as follows. In the session of text introduction, students experience the existing knowledge, i.e. reflect and orally present the background knowledge they have learned about Sports, such as a wordguess game, guess the meaning of the sports, or something related to the Chinese Kung-fu. Discuss the question "What sports do you usually do when you have PE classed?". Secondly, with the guidance of teachers, students will deeply study the theoretical concepts of the text. Thirdly, under the guidance of the teachers, students conduct functional analysis and critical analysis of the text, which is to analyze the cohesive devices of long sentences and texts, infer the author' attitude and summarize the viewpoints. Fourthly, students are given the appropriate application, e.g. the text speed reading comprehension test and vocabulary time limit test on the SPLS. Fifthly, students make a creative application, that is, group cooperation around the topic "Sports", practicing role-playing dialogue in class.

\section{After class-SPLS reviews}

The teachers prepare the unit of follow-up learning through SPLS for students and interact with students. In the after-class review stage, students can independently review the language points from PPT, class notes and other learning materials uploaded by teachers on the SPLS. Students practice what they learning through appropriate and creative application. Among them, the application of appropriateness can be divided into(1) written appropriateness application, including summarizing the key words and phrase in the text, translating the exercises after class, and uploading the homework content to the SPLS. (2) 
Oral appropriateness application, including an oral summary of the reply content, the recording submitted to the SPLS.

Creative use involves combining what you've learned with your own experience writing a letter to your friend. Suppose you are a college student of Guangxi Vocational \& Technical College. Your British Netizen, Mary, was very happy to see the photos and video you sent her of the 21st track and field games and the 3rd national sports games of your college. She is interested in it, especially Chinese Tai Chi, Dragon and Lion Dance, Long Mouth Pot Show, Bamboo Dance Show and so on. She hopes you can tell her about the origin and national spirit of Tai Chi, Dragon and Lion Dance, Long Mouth Pot Show, Bamboo Dance Show. Please write a letter according to the following: Tell Mary the advantages, history original and the national spirit of them. Warmly welcome her to your college, if she wants to come and study the above programs, you would like to contact the learning places and teachers for her. The PPT that was finished by Team cooperation uploaded to the SPLS while the composition was uploaded to the www.pigai.org.

\section{THE EMPIRICAL STUDY ON DESIGN LEARNING MODEL}

The study adopts the empirical research method combining experimental research, questionnaires, random interviews, exploring the influence of design learning model on students' multi-literacy ability and their attitude towards design learning methods.

\section{A. Experimental research}

\section{1) Teaching objects}

This study takes the college freshman of Guangxi Vocational \& Technical College who is non-English major as the research objects in 2018.

\section{2) Experimental problem}

Is the design learning model more conducive to the development of students' multi-literacies? Is the experimental class better than the control class in multiple literacies?

\section{3) Experimental arrangement}

In the third week, two classed of students complete the test. (As a freshman, the students must finish the military drills in the first two weeks).

Before the test, on a scale of 100 , they are tested for students' ability to read and write multiple ways. The test consists of two cultural reading comprehension tests (five questions per test, 2 points per test, 20 points in total). Students' ability to understand and grasp the main idea of the passage, the logic relationship, and to infer the meaning of the words from the context, as well as their ability to understand and criticize diverse cultures are mainly examined. Choose the best word to fill in the blanks for two articles. There are 10 blanks for each article, one point per question, totally of 20 points. The experiment mainly examines the language reading and writing ability of students in a specific context, for example, vocabulary and grammar ability, comprehensive comprehension ability of text and so on. Group role-plays, (60 points in total) examine students' multi-literacy from the perspective of language literacy, social communication skills and technical literacy. From the $4^{\text {th }}$ week to the $17^{\text {th }}$ week, the experimental class adopted design learning mode. The contrast class uses the traditional learning mode (leading in-explaining the text- finishing the exercises). In the $18^{\text {th }}$ week, two classes of students were tested-A test of form, difficulty, and the scoring consistency.

\section{B. Questionnaire survey and random interviews}

After the experiment, this study conducted a questionnaire survey on the students in the experimental class. The paper explores students' attitude towards design learning mode from the five dimensions of learning efficiency, language practice, overall learning effect and learning intension. The five-point Likert scale was used to score the questionnaire, $1=$ strongly disagree, 2=disagree, 3=uncertainty,4=agree, 5=strongly agree. In addition, the study also conducted random interviews in the experimental class to deeply understand the specific feeling of the class students on the design learning model.

\section{RESUlt AND DisCUSSION}

\section{A. The design learning model is helpful to improve students' multi-literacies}

TABLE I. PRETEST SCORES BETWEEN EXPERIMENTAL CLASS AND THE CONTROL CLASS

\begin{tabular}{|c|c|c|c|c|}
\hline \multirow{2}{*}{ Marks } & \multicolumn{2}{|c|}{$\begin{array}{c}\text { The experimental class (65 } \\
\text { students) }\end{array}$} & \multicolumn{2}{c|}{$\begin{array}{c}\text { The control class } \\
\text { (62students) }\end{array}$} \\
\cline { 2 - 5 } & $\begin{array}{c}\text { Number of } \\
\text { students }\end{array}$ & percentage & $\begin{array}{c}\text { Number of } \\
\text { students }\end{array}$ & percentage \\
\hline $\begin{array}{c}\text { More } \\
\text { than 90 }\end{array}$ & 1 & $1.54 \%$ & 1 & $1.61 \%$ \\
\hline $80-89$ & 14 & $21.54 \%$ & 13 & $20.97 \%$ \\
\hline $70-79$ & 23 & $35.38 \%$ & 21 & $33.87 \%$ \\
\hline $60-69$ & 20 & $30.77 \%$ & 19 & $30.65 \%$ \\
\hline $\begin{array}{c}\text { Less than } \\
60\end{array}$ & 7 & $10.77 \%$ & 8 & $12.90 \%$ \\
\hline
\end{tabular}

From TABLE I, we can see that, there was no significant difference in multiple literacy scores.

TABLE II. POSTTEST SCORES BETWEEN EXPERIMENTAL CLASS AND THE CONTROL CLASS.

\begin{tabular}{|c|c|c|c|c|}
\hline \multirow{2}{*}{ Marks } & \multicolumn{2}{|c|}{$\begin{array}{c}\text { The experimental class (65 } \\
\text { students) }\end{array}$} & \multicolumn{2}{c|}{$\begin{array}{c}\text { The control class } \\
\text { (62students) }\end{array}$} \\
\cline { 2 - 5 } & $\begin{array}{c}\text { Number of } \\
\text { students }\end{array}$ & percentage & $\begin{array}{c}\text { Number of } \\
\text { students }\end{array}$ & percentage \\
\hline $\begin{array}{c}\text { More } \\
\text { than 90 }\end{array}$ & 5 & $7.69 \%$ & 1 & $1.61 \%$ \\
\hline $80-89$ & 25 & $38.46 \%$ & 16 & $25.81 \%$ \\
\hline $70-79$ & 26 & $40 \%$ & 22 & $35.48 \%$ \\
\hline $60-69$ & 7 & $10.77 \%$ & 17 & $27.42 \%$ \\
\hline $\begin{array}{c}\text { Less than } \\
60\end{array}$ & 1 & $1.54 \%$ & 6 & $9.68 \%$ \\
\hline
\end{tabular}

From TABLE II, we can see that after a semester of higher vocational English design learning based on SPLS, the multiliteracy of the experimental class have improved significantly. There are five students can get high score. It is rare for students of college students. The number of students between from 80 to 89 rose obviously, with the number of students between 60 and 
69 falling significantly, the number of students who failed to fail appreciably decreased. The result shows that the students gained recognition in their revision and satisfied the sense of achievement.

\section{B. The design learning model is popular among students}

TABLE III. THE RESULTS OF THE STUDY ATTITUDE QUESTIONNAIRE IN THE EXPERIMENTAL CLASS.

\begin{tabular}{|c|c|c|c|c|c|}
\hline Item description & S.A(\%) & A.(\%) & S.D(\%) & D.(\%) & N.S(\%) \\
\hline $\begin{array}{c}\text { Help to improve the } \\
\text { efficiency of classroom } \\
\text { learning }\end{array}$ & $6.3 \%$ & $90.5 \%$ & $0 \%$ & $1.6 \%$ & $1.6 \%$ \\
\hline $\begin{array}{c}\text { It is convenient for me to } \\
\text { preview and review } \\
\text { independently after class }\end{array}$ & $11.1 \%$ & $85.7 \%$ & $0 \%$ & $0 \%$ & $3.2 \%$ \\
\hline $\begin{array}{c}\text { Let me have more } \\
\text { language practice } \\
\text { opportunities }\end{array}$ & $4.8 \%$ & $88.8 \%$ & $0 \%$ & $3.2 \%$ & $3.2 \%$ \\
\hline $\begin{array}{c}\text { In general, the learning } \\
\text { effect of this mode is good }\end{array}$ & $1.6 \%$ & $93.6 \%$ & $0 \%$ & $3.2 \%$ & $1.6 \%$ \\
\hline $\begin{array}{c}\text { It is necessary to adopt } \\
\text { this model for learning in } \\
\text { the future }\end{array}$ & $6.3 \%$ & $87.3 \%$ & $1.6 \%$ & $1.6 \%$ & $3.2 \%$ \\
\hline
\end{tabular}

S.A=Strongly agree, A=Agree, S.D=Strongly disagree, $\mathrm{D}=$ Disagree, N.S=Not sure.

There are 63 valid questionnaires collected from the experimental class were conducted. The results showed as Table 3. Most students $90.5 \%$ indicated that the mode can improve the efficiency of classroom learning. $85.7 \%$ of students think it's convenient to preview and review independently after class. $88.8 \%$ of students consider they have more language practice opportunities. $93.6 \%$ of students are satisfied with the learning effect of the design learning mode. Furthermore, students also expressed their recognition of the designing learning model in the interview. The model can not only enliven the classroom learning atmosphere, increasing the interaction between teachers and students, but also promote their learning enthusiasm and class participation, making them becoming center of learning. Online test/homework, resources download, classroom check-in and other functions are the most popular. They favorite the audio and video resources most.

\section{Teachers evaluation of the learning model}

Teacher evaluation mainly focuses on the following: classroom interaction is novel and high student participation. After the class review is convenient and flexible, students' independent study has been greatly promoted. Online assignments and exams are easily organized and marked, saving time and effort. Teachers are able to monitor students' learning progress, checking the completion situation and timely know about students' learning behavior.

\section{Discussion}

The advantage of design learning model in cultivating multiple literacy behavior.

The author designs and produces the course chapter content based on the course material content and support resourced. Each unit included learning objectives, word preview(audio), dialogue learning( audio and video), key sentence patterns, conversational drills (audio), learning feedback and teaching evaluation and unit tests. After the class is created, in the first period of college freshman, the invitation code is sent to organize students to join the class, and the students are guided to learn and use various functions. Except that, the author also pushes and expands resources to the students, and directly uploads some extracurricular learning resources in the form of audio, video and text. In the design learning model, students need to master the basic use and operation skills of SPLS proficiently, especially technical operation methods of completing timed answering, sending bullet screens, submitting written and phonetic homework and etc., put forward requirements for students' technical reading and writing ability. During the process of making PPT for role-playing, students can obtain relevant information through multiple channels by using network technology, learning to choose and arrange text, pictures, video, audio, font, size, color, layout and other symbol resources in PPT to express the meaning, which also effectively cultivated their technical reading and writing ability.

SPLS improve the learning efficiency of language knowledge and increase the opportunity to experience and apply existing knowledge, which can exercise the students reading and writing ability. The learning model improves the learning efficiency of language knowledge. It expands the time and space for students to preview and review the language knowledge in textbooks. In Class, students do not have to be busy taking notes or taking photos, but only need to concentrate on an in-depth study of the theoretical concepts of the text, functional analysis and critical analysis. After class, students can check the classroom notes, exercises and other learning materials pushed by teachers in the SPLS, so that students can timely sort out and consolidate the language knowledge learned in class. The combination of pre-class, inclass and after-class language learning exercise students' language reading and writing ability.

In the design learning mode, students can preview PPT before class by integrating text, pictures, video, the audio resources to experience and appreciate background knowledge related to the theme. Video, the original high-simulation cultural knowledge network carefully selected and uploaded to the SPLS by teachers, has the functions of scene reproduction and scene interaction. The students can be immersed in the vivid target language culture and situational context, which subtly improve students' social communication ability. Students have more time and opportunities to creatively apply what they have learned in class through role-playing or thematic development writing. Among them, role-playing requires students to match and combine sounds, words with pictures, facial expressions and body movements to generate communicative meaning and to negotiate and cooperate with other students, which train students' social communication ability.

\section{CONCLUSION}

Based on the SPLS and the design learning concept, the study constructs the English design learning mode of higher vocational colleges based on SPLS. From the above survey data, we can draw a conclusion that most students are glad to 
this new learning platform very much. They are quite satisfied with using it. Since mobile learning very consists of the characteristics of the current era. Students' various learning needs can be met quickly and conveniently, and their learning behaviors can also get timely feedback, to a large extent to improve the effectiveness of learning and self-learning ability. The teaching experiment results show that students' multiliteracy ability has been effectively improved. The paper further points out that this model has certain advantages in cultivating students' multiple literacy abilities such as language reading and writing ability, social communication ability and technical reading and writing ability. It is more beneficial for teachers to continue to develop and optimize the application of mobile teaching platform in future courses. English teachers can integrate design learning concepts to develop students' multiple literacy skills.

\section{REFERENCES}

[1] China Internet information center (CNNIC). Statistical Reports on Internet Development in China [Z], August 2018. (In Chinese)

[2] Zuo Yi. Practice and Thought on Applying Smart Phone Mobile Teaching Platform in the Higher Vocational English Course - Taking Superstar App for an Example [J]Journal of HUBEI Open Vocational College,pp.148-149, February 2019. (In Chinese)

[3] The New London Group. A pedagogy of multiliteracies: Designing social futures [J]. Harvard Educational Review, pp. 60-93, January 1996.R. Nicole, "Title of paper with only first word capitalized," J. Name Stand. Abbrev. In press.

[4] Zhang Delu, Exploration on the training mode of multi-modal learning ability[J] Foreign Language Research, pp.9-14, February 2012. (In Chinese)

[5] The New London Group. A pedagogy of multiliteracies: Designing social futures [J]. Harvard Educational Review, pp. 60-93, January 1996.

[6] Wu Lingjuan, Zhang Delu. (2019).Research on the Design Learning Model of General English based on Rain Classroom-Also on the Cultivation of Students' Multiliteracies [J] Modern Educational Technology,pp.78-84, March 2019. (In Chinese)

[7] Writing group of Career Express English, Career Express English Book I [M] Higher Educational Press, pp.55-71, May 2017. (In Chinese) 